\title{
O JOGO DO CAFÉ: OS SENTIDOS DO CRÉDITO/DÍVIDA NAS MONTANHAS DO CAPARAÓ MINEIRO ${ }^{1}$
}

\author{
Paulo Augusto Franco de Alcântara ${ }^{12}$ \\ ${ }^{1}$ Fundação Getulio Vargas, RJ, Brasil \\ ${ }^{2}$ Núcleo de Pesquisas em Cultura e Economia, \\ Universidade Federal do Rio de Janeiro (NuCEC/UFRJ), Brasil.
}

\section{Introdução}

O acesso ao crédito subsidiado, enquanto política pública (State Credit), não é demanda recente dos trabalhadores e dos pequenos sitiantes do mundo rural brasileiro. Na perspectiva do estímulo à entrada de recursos financeiros em cenários de escassez monetária, o crédito foi abordado pela literatura sociológica específica como possibilidade de enfrentamento de questões entendidas como cruciais na vida e na reprodução do sitiante: o êxodo rural, as relações de dominação, a pobreza e a fome (Andrade 1980).

Em especial nos governos marcados pela gestão do Partido dos Trabalhadores (2003-2016), não somente no campo, mas também na cidade, a expansão popular do crédito estruturou uma agenda econômica de Estado orientada pelas noções de "inclusão" e de "participação", ${ }^{2}$ com base no enfrentamento processual das desigualdades e no combate à fome. Os acessos ao dinheiro e ao consumo teriam sido eixos de relações entre as políticas macroeconômicas e as vidas econômicas. ${ }^{3}$

No mundo rural, o processo obteve convergência na chamada "agricultura familiar": conceito transnacional viabilizado pela Organização das Nações Unidas para a Alimentação e a Agricultura (FAO), ideia-força endereçada à valorização da produção de base familiar, à segurança e à soberania alimentar. 
No Brasil, o sentido da agricultura familiar passa a ser transmitido, sobretudo a partir dos movimentos sociais rurais, como grupo socioeconômico - sitiantes e pequenos produtores rurais cuja mão de obra é familiar - a ser organizado, em função de suas especificidades culturais e produtivas, em oposição à sociedade e ao modelo político e econômico do agronegócio.

Surge, nesse contexto, em 1995, o Programa Nacional de Fortalecimento da Agricultura Familiar - Pronaf - política pública cujo centro de intervenção é o acesso ao crédito subsidiado e direcionado ao "desenvolvimento rural sustentável" da produção local e à "geração de renda e emprego" (Grisa 2012:184).

Desde a sua criação, o Pronaf passou por diversas alterações institucionais, especialmente em razão de sua ampliação para grupos menos capitalizados. Foram criadas categorias específicas de classificação de acordo com a heterogeneidade das formas familiares de produção e de capitalização. Surgiram, assim, a partir de 1997, os grupos A, B, C e D, e o Pronaf custeio ("Pronafinho"). Na sequência, vieram, entre outros, "Pronaf Mulher" (2003), "Pronaf Jovem" (2003), "Pronaf Agroecologia" (2003) e "Pronaf Mais Alimentos" (2008), este voltado a investimentos na infraestrutura local de produção e serviços. Houve também uma unificação dos grupos C, D e E em "agricultores familiares" (2008), visando a diferentes valores com taxas de juros anuais diferenciadas (Grisa 2012:144).

O acesso a esse crédito tem como requisito a apresentação, pelos agricultores, do certificado de reconhecimento formal como agricultor familiar (Declaração de Aptidão ao Pronaf). A DAP é um documento oficial emitido por uma assessoria técnica comprovando se tratar de uma propriedade onde se exerce a "agricultura familiar". Nesse documento, o agricultor ou a agricultora deve apresentar detalhes da condição estrutural de sua unidade doméstica (número de filhos, renda mensal, tamanho da propriedade etc.), apontando, especialmente, informações acerca da constituição (familiar) da mão de obra.

A expansão do Pronaf coincide com a consolidação de aparatos políticoinstitucionais de suporte à agenda da agricultura familiar. Entre outros, destaco a criação do Ministério do Desenvolvimento Agrário (2000) e a conformação do Conselho Nacional de Desenvolvimento Rural Sustentável (CNDRS), que se tornou, depois, a sigla Condraf em referência direta à Agricultura Familiar. A noção, dessa forma, passa a ser organizada com status oficial enquanto política de Estado. No plano econômico, a agricultura familiar é mais intensamente enfatizada como possibilidade de inclusão mais efetiva de grupos sociais tidos como às margens do mercado capitalista.

O Pronaf impactou consideravelmente a agricultura brasileira desde a segunda metade da década de 1990 e, sobretudo, nos anos 2000, permitindo 
a formação e a ampliação de lavouras e pequenas propriedades rurais (Guanziroli 2007). O crédito subsidiado teria possibilitado a realização de investimentos por parte de pequenos agricultores em suas produções, assim como potencializado o consumo ordinário de famílias. Dentre os beneficiários estão não apenas pequenos sitiantes, mas também meeiros, parceiros e trabalhadores temporários.

Neste artigo, abordarei o Pronaf a partir da perspectiva de seus "beneficiários", isto é, estudando etnograficamente os usos dados por sujeitos, agricultores e agricultoras familiares, ao crédito. Isto implica considerar a política pública para além de suas expectativas formais, concentrando a investigação na vida cotidiana daquelas pessoas que a vivenciam concretamente. De partida, assumo a perspectiva do crédito na sua inseparabilidade em face da dívida (Peebles 2010).

Quais os usos e os sentidos dados ao crédito/dívida? Quais questões surgem nos planos das decisões em torno do acesso ao crédito/dívida? Quais contradições emergiriam ao longo da gestão cotidiana dos recursos? Como o advento da política pública teria impactado as esferas locais de sociabilidade dos agricultores e agricultoras familiares?

Baseio os argumentos presentes no texto na hipótese geral de que toda intervenção externa, ao invés de condicionar mecanicamente o comportamento de indivíduos, seria confrontada com repertórios locais de valores. Indivíduos e grupos sociais "beneficiários" concederiam conteúdos próprios - muitas vezes singulares e até não previstos pela norma - à intervenção (Ver, por exemplo, Geertz 1963; Ferguson 1994; Long 2003. No Brasil, Sorrentino 2011; Pires 2013; Morton 2013; Ansell 2014). Nos planos do vivido, as intervenções reorganizariam não apenas as relações sociais, mas também as subjetividades de seus beneficiários (Balen \& Fotta 2019).

Considero, então, que o sentido dado ao crédito/dívida se amplia para além da entrada de dinheiro e da obrigação do pagamento no prazo estipulado: (1) alcança também os planos das relações sociais, mobilizando seus atores em debates acerca da gestão da vida local; (2) cria confrontações internas, revelando as tensões constitutivas das decisões a serem tomadas pelas famílias diante do acesso, dos usos e das manutenções dos recursos no tempo. Essas tensões expõem os modos pelos quais os atores concebem as mudanças sociais e até a própria noção de agricultura familiar em âmbito concreto. Nesse sentido, as disputas locais entre os sentidos da autonomia vão se tornando primordiais. 
No intuito dessas indagações, entre janeiro de 2015 e fevereiro de 2018, convivi com famílias de cafeicultores residentes no município de Espera Feliz, na Zona da Mata, Caparaó mineiro. Na pesquisa, concentrei-me em uma comunidade cafeeira com 19 unidades domésticas: sítios que compreendem casas, terreiros, hortas e lavouras não somente de café, mas também de banana e mandioca.

Todos os interlocutores presentes neste artigo são sitiantes moradores dessa comunidade que chamam de córrego. Trata-se de um território vivido, habitado por famílias de cafeicultores, parentes entre si. São descendentes de três famílias cujos membros se casaram entre si, unindo os troncos e formando novas unidades familiares, ou galhos, em referência à derivação. Três desses galhos, antes moradores de meia, mudaram-se recentemente para o córrego estimulados, em especial, pelo acesso ao crédito subsidiado, pela possibilidade de formarem lavouras próprias próximas às dos pais, dos irmãos: dos parentes. A maior parte desse grupo nunca havia acessado crédito bancário antes do Pronaf. Alguns nunca haviam sequer entrado em uma agência de banco.

Pude ao longo do tempo conviver com essas famílias, estando atento ao que Malinowski sublinhou como os "imponderáveis da vida real" (1978:27-32), isto é, no contato constante e direto, observando, participando e descrevendo etnograficamente suas práticas, suas relações, à procura dos sentidos e das intenções que as presidem no tempo. Participei do cotidiano local das relações, dentro e fora de suas casas e lavouras, em ocasiões de trabalho, de lazer, de descanso, de celebração, de alimentação, em momentos de dúvidas e de decisões.

A região de Espera Feliz é conhecida nacionalmente pela beleza de suas paisagens de altitude, onde se localizam o parque do Caparaó e o Pico da Bandeira. É também região lembrada pelo protagonismo de seus habitantes na produção de um café de elevada qualidade, a qual vem alinhando, desde meados dos oitocentos, cultura e economia. ${ }^{4} \mathrm{Ali}$, o café é tido a principal fonte de sustento nas comunidades rurais do município, expandindo-se não somente nestas, mas também na formação do comércio e do turismo.

Com a expansão do Pronaf, em especial a partir de 2002, Espera Feliz tornou-se uma referência no estado de Minas Gerais na implantação desta política e do Programa Nacional de Crédito Fundiário (PNCF), ambos definidos como centrais nas ações do Sindicato dos Trabalhadores e Trabalhadoras na Agricultura Familiar (Sintraf) estabelecido no local.

Este artigo é apresentado em três seções de texto. Na primeira, introduzo o contexto etnográfico em questão por meio da narrativa de uma trajetória pessoal. Na segunda, relaciono, em termos mais gerais, os sentidos 
concedidos pelos agricultores e agricultoras ao crédito/dívida. Abordo, em especial, as relações entre a dívida e as expectativas por mais autonomia nas práticas econômicas. Na terceira seção, descrevo, enfim, as gestões do Pronaf, abordando os debates e as contradições envolvidas ao longo desses processos. Defendo que os contatos com crédito/dívida, nesse contexto, interferem tanto nos fluxos ordinários das finanças das famílias quanto nas relações sociais, nas temporalidades vividas e no próprio modo pelo qual a agricultura familiar é concebida e praticada no local.

\section{A primeira história que ouvi e o universo etnográfico em questão}

Ulisses é um sitiante de pouco mais de 40 anos de idade. Durante a maior parte de sua vida, ele, junto com sua família, morou e trabalhou na propriedade de um fazendeiro, em uma das comunidades rurais de Espera Feliz. Recordando-se do tempo em que sua família vivia sob o regime da morada de meia, ele diz que sua vida era caracterizada por uma escassa ou inexistente possibilidade de geração independente de renda. Morando e trabalhando nas terras de seu patrão, parte da produção era destinada à fazenda $(60 \%)$ e parte retornava para o consumo de sua família $(40 \%)$.

Segundo ele, o cenário começou a mudar quando o Pronaf passou a ser implementado na região, no final da década de 1990. A chegada do crédito subsidiado seria a chance para que muitos meeiros e sitiantes pudessem desenvolver as suas produções, realizando investimentos e criando possibilidades de renda. Alguns, diz Ulisses, poderiam incrementar a produção já existente, outros, na esperança de deixar a morada de meia, poderiam começar uma nova vida em terras próximas às dos pais e dos irmãos, cedidas ou herdadas. Experimentariam, segundo ele, a agricultura familiar, um projeto de vida e produção com mais autonomia.

Essas expectativas, inicialmente, foram frustradas. Durante os primeiros anos de implementação do Pronaf, a família de Ulisses viu esses recursos serem destinados, na sua maior parte, aos fazendeiros locais, cuja produção já se encontrava mais ou menos estabilizada. O pior ocorreu, segundo ele, quando seu pai, junto com outros moradores de meia, foi induzido pelo patrão a adquirir o crédito subsidiado em sua titularidade. Os valores foram integralmente repassados ao patrão, que prometia maiores investimentos na produção da fazenda, o que beneficiaria todos aqueles sob o seu domínio. 
Com a morte do patrão e sem o comprometimento de seus filhos herdeiros com o pagamento das dívidas contraídas pelos moradores de meia, Ulisses lembra que as cartas de cobrança chegavam, ao mesmo tempo em que a sua condição material o impossibilitava de resolver o débito no banco. Sem solução dada, o pai de Ulisses permaneceu até o final de sua vida com cadastro negativo no órgão de proteção ao crédito (nome sujo). Isso o impediu de realizar novas compras a prazo. A vergonha causada pela dívida fez com ele decidisse pela vida isolada no sítio, sem poder 'colocar os pés em Espera Feliz', com medo do que falariam sobre a sua situação, com vergonha.

Apesar dessa experiência negativa, Ulisses afirma que o crédito tem também um 'lado positivo' em sua vida. Com o suporte do sindicato de agricultores familiares de Espera Feliz (Sintraf), ele lembra que acessou o crédito subsidiado para a compra de terras (Programa Nacional de Crédito Fundiário). Em 'chão próprio', ele casou e teve os seus filhos. Três casas foram construídas: uma para Ulisses, uma para o seu irmão e outra para os seus pais. Lavouras de café foram plantadas com recursos do Pronaf. No sítio, Ulisses e a família plantaram também lavouras de feijão, grupos de bananeiras, hortas e construíram um extenso terreiro destinado à secagem dos grãos de café.

A partir de 2002, segundo o próprio Ulisses, hoje dirigente do sindicato local, com a expansão e a popularização do Pronaf no Brasil, Espera Feliz viveu um período de fortalecimento da pequena agricultura de base familiar. Não somente Ulisses e sua família, mas também um número de pequenos sitiantes pôde iniciar e/ou expandir suas lavouras, comprar terras e construir casas, as chamadas casinhas, adquiridas por meio do Programa Nacional de Habitação Rural (PNHR).

Assim como Ulisses, muitos outros pequenos cafeicultores do Caparaó mineiro afirmam ter se descoberto como agricultores familiares após a expansão do Pronaf no local, um grupo social cujo sentido é determinado pela produção circunscrita da mão de obra familiar e da melhoria das condições de vida no campo sob os princípios da cooperação e da produção de alimentos com qualidade. Essa construção se dá também em oposição moral e econômica ao modelo hegemônico que reconhecem como o agronegócio.

\section{A entrada no jogo e os sentidos gerais da dívida}

Assim como Ulisses, muitos outros pequenos cafeicultores de Espera Feliz deixaram recentemente as terras de seus patrões, estimulados pela possibilidade de terem casa própria (casinha) e de iniciarem uma nova 
produção fazendo uso do crédito subsidiado. Falo, em específico, de agricultores e agricultoras moradores da comunidade onde concentrei o trabalho de campo, homens e mulheres, gestores e gestoras de suas lavouras de café.

Enquanto agricultores familiares, eles afirmam ter passado a participar de um domínio econômico de relações antes tido como de acesso exclusivo dos patrões. Nomeiam como jogo do café a produção e a comercialização autônoma, em sítios e lavouras próprias. Essas operações, no conjunto, abrem um universo de novas relações, atividades, conceitos e aprendizados tomados entre decisões que podem anunciar riscos e perigos, mas também a melhoria das condições de vida. Esperam, num primeiro momento, o acesso à renda necessária para garantir a permanência e o sustento com qualidade da família na roça, espaço sempre narrado como de 'vida dura' e de dependência histórica aos patrões.

No jogo, discutem a gestão da produção, tomando decisões, criando hipóteses e aprendendo com os desafios postos pela organização do tempo, do trabalho, do dinheiro e do comércio. Sobretudo a partir do acesso ao Pronaf, interagem diretamente com compradores de café, agentes que representam as empresas locais, as firmas que promovem intermediações na cadeia de comercialização do produto, e que são vistas por explorarem os cafeicultores. A novidade implica também a tessitura de relações com comerciantes de insumos, lojistas e assistentes técnicos, por meio de negociações cotidianas em torno de preços, condições, visando a benefícios e sempre procurando evitar prejuízos.

Essas experiências, sempre imersas em um sistema de valores, são habitualmente compartilhadas entre os parentes na "comunidade moral" onde habitam (Bailey 1971). Assim como percebeu Comerford (2003) em outro contexto rural da Zona da Mata mineira, o intercâmbio de informações é comumente acompanhado pela vigilância constante tanto dos deslocamentos físicos e das relações quanto das práticas econômicas uns dos outros. Há, no córrego, entre outras, intensa atenção em como um parente está administrando o seu sítio e, por contiguidade, sobre os usos do crédito/ dívida. São partes constitutivas dos modos como o jogo é vivido o acesso privilegiado a informações sobre preços, recursos e experiências concretas da gestão da produção e do comércio do café.

Os cafeicultores jogam com casos econômicos dos parentes e de outras pessoas conhecidas. Extraem exemplos a serem seguidos ou evitados. Esses casos compartilhados poderão ajudar em momentos de dúvidas. O domínio sobre esse repertório poderá fazer com que um agricultor jogue bem, quer dizer, planeje os riscos sem colocar em perigo a sobrevivência 
diária da família. Para eles, o jogo envolve tensões entre os valores locais e as interferências possíveis de instâncias mais abrangentes, às vezes incertas e 'perigosas', como, por exemplo, as do mercado.

De uma forma geral, enxergam o Pronaf como um recurso contemporâneo crucial para a prática (entrada e permanência) do jogo. O modo pelo qual administrarão o crédito/dívida irá definir tanto o sucesso quanto o fracasso dos cafeicultores e, com efeito, as suas reputações no córrego.

Como crédito, mesmo subsidiado, o Pronaf é também dívida, parte integrante da realização da entrada do agricultor familiar no jogo. A tomada de um crédito/dívida associa-se à realização de investimentos e confirma para eles a gestão pessoal do agricultor em sua produção. Zé Amaro, agricultor familiar de quase 60 anos de idade, que em 2016 havia recentemente acessado o seu segundo Pronaf, dizia-me que a dívida pode 'ajudar' ou 'atrapalhar', ao mesmo tempo, dependendo da gestão do agricultor ou da agricultora. No entanto, nunca será algo 'bom', em si.

Ele explica que essa entrada no jogo pode anunciar tensões. Se, por um lado, pode viabilizar um processo de realização de autonomia, por outro lado, o crédito/dívida, como investimento, pode ser associado à figura dos antigos patrões, pois, no passado recente, só eles - proprietários das terras, da produção, dos recursos - podiam jogar.

Zé Amaro e sua irmã Vera entendem que crédito/dívida seriam recursos próprios à 'ganância' dos patrões e, portanto, em relação de contiguidade com a exploração sofrida por aqueles moradores de meia que hoje vivem em terras próprias como agricultores familiares. Há, dessa forma, uma oposição entre as noções de passado e presente no sentido de se evitar a reprodução de modelos 'velhos' e 'antigos' para fazer 'diferente'.

A percepção sobre a entrada no jogo, de certo modo, confunde-se com a própria noção do crédito/dívida. Na compreensão - sempre contemporânea do passado, os cafeicultores identificam genericamente a dívida em sentidos variados. Além do incremento ao consumo ordinário das famílias, a entrada de dinheiro pode, por um lado, auxiliar na conjugação da insuficiência de capital com a obrigação de continuidade da produção e da ampliação das lavouras e da infraestrutura dos sítios. Mas, por outro lado, como diz Zé Amaro em concordância com seus cunhados Vitorino e Juca, uma só dívida poderá criar e manter laços de dependência, como uma 'prisão'. A situação tende a denotar tanto a vulnerabilidade e a 'vergonha', sobretudo para os homens, quanto a 'ganância' historicamente associada aos patrões.

Na dimensão da realização de investimentos para o crescimento da produção, e na formação de laços de dependência, o sentido dado à dívida tem uma historicidade no local. (1) As dívidas são vistas como aquelas 
contraídas diretamente com os patrões que, sob a forma de um 'adiantamento da produção', consignavam em pagamento a própria parcela de produção auferida pelo meeiro e/ou morador de meia; (2) Podiam ser feitas com compradores de café, conhecidos agiotas; (3) Ou serem adquiridas pelos próprios patrões que as convertiam em regimes mais intensos de trabalho, visando ao aumento da produção.

O fiado ocorria como compra a prazo nas vendas locais sobre ele se cobravam juros em torno de $16 \%$, tendo-se o patrão como fiador - financeiro e moral - da dívida. Contam que as cobranças dessas dívidas vinham acompanhadas por eventos nos quais meeiros e fazendeiros poderiam ser publicamente expostos. Em muitas situações, ocorriam confiscos de bois e de itens da produção interna das famílias. Isto explica, pelo menos em parte, a 'vergonha' do pai de Ulisses diante da cidade.

De partida, a dívida, enquanto elemento constitutivo da participação de pequenos agricultores familiares, antes vinculados ao trabalho em terras de patrão, no jogo do café, é uma possibilidade entre muitas de expressão da cultura local.

Enquanto modo específico de variadas possibilidades de manipulação de dinheiro, a dívida abarca um conjunto de sentidos e valores, às vezes opostos entre si, que constroem o mundo onde esses agricultores e agricultoras se percebem inscritos. A dívida, de acordo com o que pensam hoje, ao mesmo tempo em que dissimula, também revela processos sociais, valores e moralidades, entre práticas permissivas e práticas de interdição. Assim como os sentidos dados ao dinheiro, a dívida afeta práticas sociais (Zelizer 1994:211). É o que desenvolverei na sequência.

\section{As gestões do Pronaf}

Vitorino é um cafeicultor de pouco mais de 70 anos de idade, aposentado, pai de quatro filhos. Desde que se mudou com sua família para o córrego, em sítio próprio, ele acionou o Pronaf em algumas situações, mas, ao longo dos anos em que eu o visitei com frequência, ele procurou colocar fim ao uso do crédito, à dívida contraída.

Com o recurso, ele investiu na própria lavoura localizada em parcela herdada por sua esposa Pilar (pouco mais de um alqueire de terra), comprando sementes, adubo e um tratorito usado para capina na lavoura (Pronaf Custeio). Na sequência, comprou uma moto para o seu filho Binho que, há tempos, desejava um automóvel. Na vida de Vitorino e de sua 
família, o crédito funciona como um 'dinheiro rápido' que torna possível um investimento e/ou uma aquisição imediata de um bem que, de outra forma, dificilmente poderia ser alcançado.

Ele e o filho Mecão investiram na formação de uma horta de alfaces hidropônicas (Pronaf Investimento) e edificaram uma estufa visando à melhoria do processo de secagem dos grãos de café (Pronaf Mais alimentos). Em todos esses investimentos, a família esperava desenvolver a produção, fazendo com que o dinheiro recebido do Pronaf fosse revertido em novas e mais qualificadas fontes de renda dentro do sítio. Tendo completado essa reversão, esperavam se ver livres da dívida. A chegada dos recursos lhes trazia sentimentos de esperança em relação à melhoria das condições de vida.

Mas o dinheiro que vem 'rápido' deverá, após um ano, ser quitado, caso contrário, o crédito poderá não ser renovado pelo banco (reformado) e, então, novos recursos estarão bloqueados, isto é, um novo Pronaf não poderá ser adquirido. Esta possibilidade é vista pelos agricultores como uma interrupção nos investimentos iniciados, os quais precisam ser alimentados ao longo do tempo. Foi na pressão produzida durante a gestão desse prazo que Vitorino e Pilar começaram a se 'enrolar'.

O prazo considerado curto para o pagamento do crédito/dívida interfere na velocidade $e$, consequentemente, na intensidade com que os agricultores e agricultoras administram as suas finanças domésticas. Percebem um constante 'aperto' de ordem financeira diante do vencimento do Pronaf. Esse prazo é sentido como uma ameaça concreta a mobilizar um conjunto de esforços que articulam e constrangem a percepção e a gestão do tempo, a intensidade a ser dada ao trabalho, a qualidade do comércio a ser realizado e, enfim, a organização das finanças de indivíduos e de unidades domésticas. Na ordem dos sentidos, o crédito - 'dinheiro rápido' e 'benefício' - torna-se efetivamente uma dívida que 'aperta'. Segundo Vitorino, 'pinica feito formiga', incomodando, ocupando a mente e invadindo o bem-estar cotidiano.

A questão em torno do prazo de pagamento do crédito subsidiado anuncia uma constatação compartilhada no Caparaó cafeeiro: 'o Pronaf só ajuda uma vez'. Explicam que, no primeiro contato, a entrada de dinheiro $(2,3,5$ mil reais) não é condicionada ao pagamento de quantia anterior. É um dinheiro que chega livre de prestações devidas. Isto quer dizer que, na ordem dos sentidos, no início o recurso é crédito, mas, no decurso do tempo, sobretudo na hora do vencimento, torna-se dívida. Enquanto crédito, o dinheiro recebido é imediatamente aplicado, assumindo a forma da conquista concreta de um bem, de um investimento visível e exemplar no 
cotidiano. A quantia chega como uma novidade, 'um dinheiro que cai do céu', desvinculado de uma produção anterior a ser mobilizada ou de investimento laboral, autoexploração destinada ao pagamento da prestação devida.

Em um curto espaço de tempo, meses, Pilar e Vitorino viram a nova plantação diferenciada de alfaces não se desenvolver, e a lavoura de café, ainda nova, não corresponder tão prontamente aos investimentos feitos com o auxílio do Pronaf. Para não deixar a família completamente descapitalizada e, portanto, impossibilitada de manter o investimento que iniciara na lavoura, Vitorino acionou um microcrédito na cooperativa local para quitar integralmente o Pronaf adquirido no ano anterior. A quantia restante seria usada para a compra de sacos de adubo. Para quitar uma dívida vigente, ele adquiriu um novo crédito, recuperando a sensação de um novo ' dinheiro rápido'.

Uma lavoura maior exige um número maior de insumos. Para a moto do filho funcionar é necessária a compra de combustível e, eventualmente, manutenção mecânica. Isso quer dizer que a realização de novos investimentos na produção e a aquisição de bens trazem a necessidade de se 'fazer mais dinheiro' e, consequentemente, exigem uma gestão mais complexa de cálculos. Descrevem reiteradamente essa situação como 'falta de sossego', um 'sacrifício', uma ansiedade de pagamento, de reforma do Pronaf à espera de novos recursos para manter o movimento de investimentos.

Com a gestão urgente das finanças, Vitorino percebeu a redução das suas possibilidades de decisão. Em 2015 e 2016, vendeu o seu café às pressas, sem poder esperar uma melhoria nos preços. Isto lhe trouxe uma impressão angustiante de que as perdas pareciam maiores do que os ganhos. Mesmo assim, ele conseguiu ponderar em face da situação, afirmando sentir satisfação por não ter pedido ajuda aos parentes. Esta foi uma condição para que a sua vida permanecesse na ordem do reservado, mesmo que os investimentos feitos no córrego, como, por exemplo, a construção da estufa e a compra da moto, em certo sentido já indicassem, na visão dos outros, o seu endividamento. Parcialmente protegido da exposição de sua família na comunidade ("moral"), o crédito teria menos cara de dívida.

A última medida tomada por Vitorino durante o período de nosso contato foi a contratação de um crédito maior no banco, com prazo de cinco anos para pagamento (crédito consignado)..$^{5}$ Com esse recurso, ele conseguiu pagar tanto os Pronaf que acumulara quanto a dívida com a cooperativa. Disse que o pouco que lhe sobrou foi consumido por pequenas despesas na lavoura. Vitorino tornou-se um cliente mais frequente do banco. 
Zé Amaro apresenta semelhanças e divergências no que diz espeito às visões de Vitorino e da irmã Pilar. Para ele, o crédito subsidiado deve proporcionar ao pequeno produtor a realização de investimentos em suas lavouras. Mas, para que isso aconteça, mesmo com o prazo curto de pagamento, é necessário que o agricultor vire a sua dívida, ou seja, que, ao realizar o pagamento do Pronaf, o faça com recursos advindos da própria venda do café. É ainda necessário que sobre uma quantia que deverá ser reservada para um novo investimento na lavoura e para a manutenção das despesas básicas da unidade doméstica ao longo do ano seguinte.

Emanuel, assim como Vitorino e Zé Amaro, fez investimentos usando os recursos do Pronaf. Num primeiro momento, a coincidência com a melhoria do preço do café no mercado fez com que o cumprimento das agendas de pagamento do crédito subsidiado ocorresse sem que houvesse interferências na manutenção das despesas de sua família. No entanto, na sequência, ele viu o preço pago pelo seu café cair no mercado. A qualidade de suas sacas, que antes podiam ser vendidas a $\mathrm{R} \$ 500$ ou $\mathrm{R} \$ 600$ cada, passou a ser avaliada pelos compradores, em média, a $\mathrm{R} \$ 400$.

O caso de Emanuel é comum no córrego, fazendo com que os cafeicultores vejam com críticas o fato de o crédito ser oferecido pelo governo sem que haja uma política de preços que considere as contingências específicas da produção de café. É uma preocupação o fato de os recursos financeiros e seus prazos não mudarem quando as condições se alteram. Estas podem ser ditadas não somente pelo mercado, mas pela própria natureza: períodos de estiagem e de eventuais geadas são capazes de destruir lavouras inteiras.

Emanuel 'enrolou-se' com os prazos curtos para o pagamento de suas dívidas com o Pronaf. Isto se deu pela associação da variação dos preços com a necessidade de pagar pela mão de obra extra exigida pela expansão da lavoura de café e os gastos advindos da manutenção e do combustível para as máquinas que adquiriu. Assim, ele se viu obrigado a vender o seu café com pressa, mesmo com o preço da saca no mercado em baixa, o que o faz acreditar que dívida acaba por favorecer, ao final, os compradores de café, o mercado.

Em um dos momentos de dificuldade com o preço do café, visando pagar a dívida para reformar o Pronaf, Emanuel adquiriu, com um de seus compradores, um crédito de R\$2.000. O valor seria destinado ao investimento nas duas colheitas seguintes, as quais, ele esperava, seriam mais prósperas. A dívida auferida junto a um comprador, geralmente usada para atravessar dificuldades financeiras, é nomeada como ponte ou pinguela. Na ponte, além do pagamento em dinheiro devido, os agricultores ficam obrigados a 
vender o seu café ao comprador que lhes emprestou o dinheiro. Essa dívida contraída, no caso de Emanuel, para o pagamento do Pronaf, reduziu ainda mais as suas possibilidades de manobra na negociação de preços. ${ }^{6}$

É comum ouvir que determinada firma está em vias de falência, que o comprador está prestes a 'quebrar'. Podem ser 'alardes' e podem ser 'fofocas', como dizem. $\mathrm{O}$ fato é que os nomes desses compradores de café estão sempre presentes em rodas de conversas celebrações religiosas, festas familiares, contextos de visita, encontros eventuais nas praças de Espera Feliz, feiras, bancos e no sindicato. Nas notícias, as situações financeiras desses atores e de suas firmas oscilam, informando decisões acerca de para quem o café deverá ser vendido na próxima colheita, sobre qual comprador deverá ser digno de confiança dos agricultores e das agricultoras.

Ao interpretar esse cenário, Emanuel considera que o pequeno agricultor familiar fica, por um lado, nas 'nas mãos do governo' e, por outro, 'nas mãos do mercado'. Ao procurar o recurso em um plano, cairá nas 'armadilhas' do outro; na urgência de reformar um Pronaf, faz-se uma ponte com um comprador. Para se quitar uma ponte, aciona-se um Pronaf em nome próprio ou na titularidade de um/a filho/filha, caso já exista outro em vigência naquela família. Um esforço em direção à autonomia poderia resultar, paradoxalmente, em perda de liberdade.

Com o advento do crédito subsidiado, era esperado que ocorresse um enfraquecimento nas formas estabelecidas de sujeição dos pequenos agricultores. Nesses casos, não há somente a força dos patrões e os empréstimos com os compradores (agiotas), mas também a prática de empréstimo de sacas de café a juros entre parentes e vizinhos.

Nessa forma de empréstimo, o produto assume a qualidade de uma verdadeira moeda a indexar e criar padrões econômicos a partir da percepção e da vivência social de valores. ${ }^{7}$ Da parte de quem empresta há uma espécie de dever de ajudar um parente num momento de dificuldade: em tempos de colheita menor e quando surgem despesas não previstas na ordem doméstica e pessoal. Assim também ocorre quando a situação de 'aperto' com as dívidas é grande. Juros são auferidos na forma de sacas de café, isto é, se Vitorino pega 20 sacas com o cunhado Juca, no ano seguinte deverá lhe pagar 22 sacas.

Com o Pronaf, essa prática foi reduzida. Porém, alguns consideram uma 'substituição'. Juca afirma que simplesmente se troca a fonte, que agora são, cada vez mais, o governo e o banco, e não mais os parentes. Há uma substituição de agiotas, segundo ele. Os bancos e o governo, por meio das gramáticas de serviços e produtos financeiros, passam a fazer parte do contexto de sociabilidade na comunidade. 
Nos planos das incorporações dessas novidades, os agricultores percebem que algumas práticas são insistentes e resistentes. Dizem uns que 'é difícil mudar a cultura do povo'. Outros defendem a continuidade de algumas práticas que dizem fortalecer laços de solidariedade, como é o empréstimo de sacas de café entre parentes. Afirmam a consistência dessa forma solidária com o próprio sentido vivido da agricultura familiar enquanto lugar, por excelência, de cooperação entre os 'pequenos produtores'. Nesse ponto, o Pronaf pode ser lido por alguns como uma contradição da própria agricultura familiar, no modo com que a pensam, pois estimula uma espécie de atomização inserida no desejado processo de autonomia das famílias de agricultores. É cada vez mais 'cada um na sua', diz Inês.

Em outras palavras, é possível dizer que, mesmo sofrendo interferências de racionalidades externas, 'de fora', o "homem" do local, como diria Bailey (1971), praticará a sua racionalidade econômica como marido, irmão e pai, em consonância com os seus costumes e valores. Em outra perspectiva, Geertz (1963:82) diria que esses costumes anteriores a qualquer intervenção seriam, eles mesmos, necessários à realização dos empreendimentos "modernos" associados às transformações socioeconômicas. Isto leva os agricultores a perceberem as mudanças que vivem por meio de sínteses entre estabilidade e mudança, entre passado e presente. Como apontou Sahlins (1990:171-189), a transformação na cultura é também uma forma de sua reprodução. Assim, as formas culturais seriam capazes de abarcar o extraordinário contido no presente de modo que os indivíduos que significam essa ordem também reagissem às mudanças de acordo com os seus próprios interesses.

A incorporação do Pronaf teria, desse modo, criado um campo de debates no qual são levantadas, a todo momento, as tensões constitutivas dos usos do crédito/dívida de acordo com os impactos concretos desses recursos percebidos pelos agricultores em suas vidas. Contradições e ambivalências surgem em contextos locais e tornam-se desafios próprios ao jogo em relação à construção de um projeto de autonomia na produção cafeeira familiar. Como conjugar e alinhar práticas estabelecidas na comunidade moral com as novidades percebidas nas chamadas intervenções externas?

\section{Hipotecados e meeiros}

Floripes fez algumas dívidas nos anos anteriores a 2017. Em razão de alguns 'apertos' quanto aos prazos de pagamento do Pronaf, ele pegou sacas de café emprestadas com Zé Amaro, vizinho com quem realiza a meação enquanto não consegue plantar uma lavoura própria ao redor de sua casinha recém-construída. 
Naquele ano, Floripes havia liquidado todos os seus Pronaf. Dizia preferir 'não ter as coisas' a ter que ser meeiro de banco. Ele pensa que enquanto a dívida não está quitada, a pessoa fica vinculada, atada a alguém ou a alguma instituição; que esse vínculo/constrangimento - feito uma meação - torna boa parte da produção consignada a uma destinação prévia, que é o pagamento da dívida.

Para Floripes, não se trata de uma meação qualquer, mas de uma meação com o banco e isso é muito pior do que ser meeiro na produção de Zé Amaro, por exemplo, que é pessoa próxima, conhecedor de suas condições, passível de diálogo entre amigos. Com o banco e/ou com o governo, por outro lado, 'não tem conversa'. Isso representaria um retrocesso na vida recém-conquistada, vendo nesse endividamento uma associação com o passado próximo, quando ele e outros vizinhos da comunidade moravam e trabalhavam em terras de patrões.

Alguns agricultores discordam de Floripes. Alípio, com pouco mais de 20 anos de idade, acredita que é muito difícil prosperar no meio rural se não houver qualquer contato com um crédito/dívida. Para ele, o recurso disponível viabiliza investimentos em suas lavouras num contexto em que o dinheiro é ainda escasso. Alípio pensa o crédito como um impulso necessário ao agricultor familiar, assim como foi para os patrões quando ainda não eram 'ricos'. Estes teriam, no seu entendimento, arriscado no crédito, transformando-o em crescimento econômico. Por outro lado, ele concorda com Zé Amaro: acredita que, para isso ocorrer, a gestão do crédito deve ser feita com responsabilidade, 'usando a cabeça', não sendo mente fraca como, talvez, diz ele, tivesse sido Vitorino.

As dívidas, como parte fundamental e cada vez mais presente na gestão das finanças pessoais dos agricultores da região do Caparaó, são pretextos para longas conversas nos quintais das casas, no bar da comunidade, na porta da igreja, envolvendo majoritariamente homens, mas também posicionando as mulheres cada vez mais próximas desses cálculos, do jogo.

Nessas reuniões, os agricultores e as agricultoras buscam ouvir os rumores que envolvem os endividados, que são nomeados de hipotecados, pessoas cujos bens adquiridos ainda não foram quitados. Seriam eles, portanto, não inteiramente donos desses bens que exibem publicamente. Trata-se de sanções morais ao endividamento nem sempre explícitas (Firth 1964:32), como um fato capaz de explicar no local o sucesso e a sorte de uns, e o fracasso de outros. Explica também o sentido dado ao dinheiro proveniente de uma operação de crédito: um dinheiro que, ao final, mesmo que provisoriamente, não pertenceria de fato ao agricultor. Como visto, o maior receio de Vitorino era sofrer essas sanções e, por isso, procurava se livrar do Pronaf sem pedir ajuda. 
Mas, com os hipotecados, a gente de mente fraca ou até os meeiros de banco, o que está em jogo não é apenas o orgulho e a imagem dos sitiantes, mas toda uma noção de tempo e de mudança social baseada na conquista daquilo que entendem como a agricultura familiar, antes de mais nada, como um ideal de autonomia. Os que temem o crédito o veem em relação aos regimes históricos locais baseados na dependência, na sujeição pessoal e na imobilidade social. Os outros se apoiam nas experiências daquelas pessoas que conseguem virar as dívidas, incluindo os Pronaf, ou seja, que as transformam em fontes concretas e viáveis para que novos recursos voltem a entrar na gestão. Para isso, como afirma Alípio, não tem como não ser, em algum sentido, um hipotecado, afinal, é o preço que se deve pagar pela entrada no jogo. Desenvolve-se, nesse sentido, um debate local em torno da noção de autonomia - quase metonimicamente à agricultura familiar - que nada tem de óbvio e resolvido entre os agricultores.

Alípio tenta convencer o sogro a adquirir um Pronaf para realizar investimentos mais ousados na ampliação e na modernização de suas infraestruturas de produção. Ele visa à melhoria na qualidade de seu café para, então, colocar fim à dependência em relação aos preços dados pelos compradores. Mas Juca afirma que o crédito só traz problemas ou 'amolação' e que prefere manter a sua produção como está do que passar a vida administrando dívidas junto a credores e prazos externos. Juca diz não querer se tornar um hipotecado.

O modo com que Alípio argumenta sugere a imagem de um andaime em uma obra: as dívidas seriam um recurso provisório necessário a um empreendimento inicial, mas que, com o tempo, deveriam ser removidas sem que a estrutura de investimentos ficasse prejudicada. As dívidas, nessa interpretação, podem ser manipuladas de forma a subverter as ordens postas, as redes e os padrões econômicos estabelecidos. Usa-se, dessa maneira, uma ferramenta do sistema econômico para usá-lo em favor próprio. Talvez Alípio concordasse com E. P. Thompson (1971) e James Scott (2002) no que diz respeito à defesa de formas cotidianas práticas para limitar a ação das classes e dos processos dominantes.

Já Juca, ao abordar a dívida como um novo 'cativeiro' à disposição de um trabalhador livre, talvez pensasse mais próximo de Martins (2010:47), ou do próprio Marx, ao ver o recurso, afinal, como intermediação - na forma do capital - que subordina processos sociais inteiros, indo além do trabalho nos termos específicos da produção (capitalista). A dívida - ao dissimular processos - alcançaria os planos da vida privada, da moralidade, produzindo problemas e interferindo nos modos com que as relações sociais são vividas no local. Nesta perspectiva, ela é percebida como ameaça, 
individual e socialmente: pode ser preocupação, prejuízo e dano à reputação. Uma intervenção externa (Pronaf), não há dúvida, interfere tanto nas relações sociais quanto nos domínios da subjetividade, tal como afirmam Balem e Fotta (2019).

O debate entre sogro e genro se desenvolve no tempo à procura de acordos, de pontos de contato entre as visões. Ambos sabem que a discordância tem por base um fator geracional. Juca presenciou por mais tempo o regime de sujeição ao modelo de produção dos patrões, enquanto Alípio cresceu em meio ao projeto otimista da agricultura familiar. Essa tensão geracional está presente em outras famílias do córrego.

Juca vê nos mais jovens um uso imprudente do crédito que, segundo ele, deveria ser apenas voltado a investimentos previamente definidos e diretamente ligados à lavoura de café. Mas o 'dinheiro rápido' seria também mobilizado para o consumo de bens tecnológicos domésticos, como panelas elétricas, televisores, computadores, e para veículos, como carros e principalmente de motocicletas, como nos casos de Alípio e dos filhos de Vitorino. Pensando sempre nos hipotecados, Juca também vê os recursos do Pronaf cobrindo despesas não previstas ou pouco prováveis de ocorrer no curso dos dias, como, por exemplo, a compra de medicamentos, a realização de uma festa de casamento ou de aniversário. Nesse sentido, a entrada rápida do dinheiro volta-se, ao mesmo tempo, ao investimento na produção e ao consumo ordinário, servindo de alívio urgente na gestão de dificuldades da vida.

No caso de alguns, a dívida teria sido incorporada à gestão ordinária das finanças pessoais e familiares e, a partir daí, produziria efeitos. Os usos do crédito, de modo semelhante ao que observou James (2014) sobre o contexto sul-africano, têm relação com mudanças nos hábitos de consumo, considerando-se um espectro de "aspirações" gestadas na possibilidade concreta de existência e realização, no caso do Caparaó cafeeiro, de um 'dinheiro rápido'.

Mas a incorporação desses novos hábitos pode ser vista por alguns Juca, Floripes e, de certo modo, Zé Amaro - como prática própria daquelas pessoas de mente fraca, as quais, ao invés de realizarem investimentos na produção local, usam esses recursos no consumo de bens e serviços tidos como passageiros, ou seja, que não deixarão legados relevantes para o desenvolvimento da economia da unidade doméstica. As decisões sobre a gestão financeira (do crédito/dívida), desse modo, permanecem no plano da gestão de moralidades.

$\mathrm{Na}$ visão local, pessoas de mente fraca consomem mais do que poderiam ou deveriam consumir; compram uma motocicleta ou um carro, endividando-se, para exibir aos outros. Para estes, o Pronaf não surtirá o 
efeito desejado, voltando os seus recursos, ao final, para fora da lavoura e do próprio município, obtendo impactos negativos na economia local, como percebeu Sorrentino (2011:106) num contexto de implantação pioneira do Programa Fome Zero.

Mas há contraponto possível. Tanto nas esferas locais quanto na literatura especializada, por mais que se possa interpretar a reformulação dos hábitos de consumo nas chaves da "evasão de divisas" e de um pretenso "consumismo" (Sorrentino 2011:129), é possível também compreendê-los de outra forma. Esses usos do Pronaf podem ser concebidos em meio a táticas diretas e indiretas voltadas ao bem-viver local, mesmo não se conectando imediatamente com aqueles investimentos tidos como ideais ou próprios à "boa" gestão, segundo alguns.

Nessa linha de pensamento, Maurício, filho de Vitorino, decidiu-se pela compra de uma motocicleta que, entre outros, o auxiliaria em deslocamentos mais ágeis entre o seu sítio e as lavouras, entre a zona rural e a cidade, lugar onde costuma visitar compradores de café e realizar compras destinadas às despesas de sua família e à própria lavoura. Com a compra de um computador e a decisão pela contratação de um serviço de internet via satélite, Vera, irmã de Zé Amaro, pôde acompanhar as variações dos preços do café no mercado, ajudando-a a fazer melhores negociações com compradores de café.

Finalmente, uma síntese possível. As visões sobre o acesso e os usos do crédito subsidiado no Caparaó associam-se a disputas na comunidade sobre o sentido dado à autonomia. Por um lado, expressam o crédito como uma possibilidade de alcance da autonomia no sentido econômico da reprodução da unidade doméstica. Como Alípio destacou, tratar-se-ia de uma espécie de dívida produtiva e temporária. Por outro, apresentam o crédito, como Juca, como antagonista da liberdade: uma dívida que, após a primeira entrada de dinheiro, aprisiona o cafeicultor, cuja produção se torna condicionada ao pagamento contínuo dos montantes contraídos. O agricultor familiar transforma-se em meeiro de banco ou poderá ter sua imagem associada aos antigos patrões: hipotecados com mente fraca. Isto quer dizer que, nessa linha, para além das críticas mais técnicas à aplicação do crédito, as tensões serão, afinal, de ordem histórico-moral, ligadas, em especial, às negociações dos sentidos de autonomia e liberdade.

No debate realizado pelos agricultores o que está em jogo não é apenas a conquista de autonomia nos termos da política pública, transmitida pelo sindicato local, mas da busca e da manutenção de vidas cada vez mais livres. É nesse domínio de relações que a dívida - nos sentidos dados a ela na vida local - pode se tornar um investimento, uma prisão, uma ambição 
desmedida, uma motocicleta, até mesmo poderá custar a reputação de quem venha a contraí-la. No jogo do café, os agricultores familiares levarão esses elementos em consideração.

\section{Considerações finais}

A discussão de fundo deste artigo aborda o problema mais amplo das intervenções governamentais voltadas ao desenvolvimento em contextos locais, em especial, na oferta de crédito subsidiado a pequenos agricultores familiares (Pronaf). Analiticamente, assumi a perspectiva dos usos dados a esse crédito. Defendi que toda intervenção, ao mesmo tempo em que interfere, será ela mesma assimilada e sintetizada pelos costumes, valores e relações de seus executores "beneficiários", os quais concederão conteúdos muitas vezes não previstos nas formatações oficiais dessas políticas.

Essas intervenções, sobretudo no contexto rural brasileiro das duas últimas décadas, são associadas ao reconhecimento das diversidades econômicas e culturais presentes na conformação da chamada "agricultura familiar" (Garcia Jr. \& Heredia 2009). Mas também argumento que se inserem num processo mais amplo, de possíveis relações entre acesso ao crédito, mobilidade social e práticas econômicas das classes populares (Ver, por exemplo, Villareal 2004; Müller 2014; James 2014).

Neste artigo, analisei etnograficamente os usos do crédito subsidiado (Pronaf) numa comunidade cafeeira do Caparaó mineiro, abordando, particularmente, os sentidos dados à dívida e ao endividamento por famílias de agricultores. Vivida, ao final, como indissociável do crédito, a dívida é vista, de partida, como peça de um jogo local: domínio de ambiguidades que envolve desde a possibilidade de conquista de uma produção mais autônoma em relação a um passado de sujeições pessoais e dependência até os perigos da má gestão e da perda paradoxal de liberdades conquistadas.

Em meio aos aprendizados e às incertezas percebidas nesse jogo, o Pronaf é praticado como um 'dinheiro rápido' cujo principal desafio não é apenas a sua quitação no prazo e a renovação para um novo crédito, mas também a sua conversão em melhor qualidade de vida para os agricultores familiares. O sucesso ou não desta expectativa revela as moralidades na gestão financeira e na própria compreensão da dívida.

No debate travado no local, alguns poderão ser vistos como hipotecados, meeiros de banco e mentes fracas. Nestes casos, afirmam: 'o Pronaf só ajuda uma vez'. Outros poderão virar a dívida, obtendo da própria lavoura o sustento necessário para a reprodução da unidade familiar. 
Argumentei que o crédito/dívida, em muitos casos, incorpora-se à gestão de fluxos ordinários das finanças das famílias, direcionando usos para além da produção de café. Assim, demostrei que o crédito não significa apenas o acesso concreto ao dinheiro, mas, em diálogo com Zelizer (1994), um marcador importante de sentidos dados a esse dinheiro e aos seus usos, interferindo nas relações sociais e nas subjetividades, promovendo tensões, desafios e aprendizados: substâncias ativas das mudanças vivenciadas pelos agricultores e pelas agricultoras familiares do Caparaó nos últimos anos.

Recebido em 04 de setembro de 2019

Aprovado em 27 de maio de 2020

Paulo Augusto Franco de Alcântara

Doutor em Antropologia Cultural pelo Programa de Pós-Graduação em Sociologia e Antropologia (PPGSA/IFCS/UFRJ). É pesquisador da Fundação Getúlio Vargas, do Núcleo de Pesquisas em Cultura e Economia (NuCEC/UFRJ) e do Instituto de Economia Real (IER). Possui experiência nas áreas de Antropologia e de Sociologia em sua interface com Economia, História e Estudos da Imagem, trabalhando principalmente com os seguintes temas: práticas econômicas ordinárias; transformações sociais; história das ideias e pensamentos sociais no Brasil; vida cotidiana na e pela memória; arquivos privados e trajetórias pessoais; cultura visual. É autor e organizador de livros e coletâneas, dentre outros, Raymundo Faoro. A República em Transição (2018), e A Invenção do Mercado (2020).

https://orcid.org/0000-0003-1256-0630

E-mail: guto.franco@gmail.com

\section{Notas}

1 A pesquisa que deu origem a este artigo contou com o financiamento da Coordenação de Aperfeiçoamento de Pessoal de Nível Superior (Capes). Agradeço a Jess Reia e a Martin Fotta pelas críticas generosas, aos pareceristas e corpo editorial da Revista Mana. Agradeço ao Núcleo de Pesquisas em Cultura e Economia (NuCEC) - nas pessoas de Federico Neiburg, Fernando Rabossi, Eugênia Motta, Gustavo Onto e Viviane Fernandes - que muito estimulou o debate presente neste artigo.

2 Utilizo itálico para as categorias nativas ( $\mathrm{x}$ ); aspas simples (' $\mathrm{x}$ ') para falas dos interlocutores; aspas duplas (" $\mathrm{x}$ ") para citações à bibliografia e para problematizar expressões. 
3 Como estratégia global, a promoção do desenvolvimento por meio da inclusão ou da participação no mercado não é novidade. As possibilidades de abordagem passam por planos e críticas variados, surge da gramática da produtividade (World Bank 1975), segue a formação de uma institucionalidade consensual das práticas de intervenção voltadas à integração e à redução da pobreza (Craig \& Porter 2006), a consolidação de organizações especializadas (Escobar 2010) em direção da formação de uma "ciência" voltada ao desenvolvimento (Mosse 2005), e atingindo a ideia da intervenção como controle social (Ferguson 1994). Isso tudo diz, ao final, que a oferta de crédito situada em projetos governamentais de desenvolvimento passou a constituir e a coincidir com a ideia de intervenção, a qual, sob derivações do Welfare State, foi tomando a imagem de políticas públicas, legitimando, mesmo que de modo abstrato e generalizado, grande parte das agendas dos governos. Essa configuração compõe uma das dimensões mais importantes presentes no complexo processo de conjugação entre o capitalismo contemporâneo e a democracia, sob a linguagem da parceria e da participação.

4 No estado de Minas Gerais, a Zona da Mata destaca-se como referência no cultivo e na exportação do café. A própria definição regional é especialmente atrelada à sua identidade econômica, que seria fruto de uma rede de cidades e unidades de produção ligadas a centros relacionados à comercialização e ao escoamento, mobilizando uma integração econômica em torno do café (De Paula 2006:78). Essa identidade, associada à vocação, à predestinação geográfica e humana - altas montanhas e braços dispostos - abrange escalas variadas: está tanto nas narrativas mais abrangentes do Estado quanto nas locais, dos agricultores e das agricultoras. Para uma breve história do café na região do Caparaó mineiro, ver Lanna (1986); Mercadante (1990).

5 Trata-se de empréstimo pessoal com banco público, nesse caso, direcionado ao aposentado. O débito automático e direto no recebimento mensal da aposentadoria faz com que os juros praticados sejam reduzidos. A modalidade ganhou protagonismo no Brasil a partir de 2004

6 As pontes são vistas como recursos que criam e/ou desenvolvem relações de confiança entre um agricultor e um comprador de café, sugerindo uma fidelização do primeiro para com o segundo. O segundo, além da exclusividade na relação de compra e venda, ganha um maior poder na definição do preço a ser dado ao café, podendo, inclusive, diante da possibilidade desse ganho, deixar de cobrar juros do agricultor devedor. O segundo geralmente se sente honrado por ter sido digno da confiança de um comprador, dizendo, como Vitorino, que "nunca deu tombo", ou que deixou de pagar uma dívida. A confiança gera boa fama para os agricultores, podendo render-lhes futuros negócios e benefícios.

7 Os usos do café como moeda têm registro no sistema de colonato paulista do século XIX, quando os credores de fazendeiros insolventes preferiam o confisco de sacas de café ao invés de prosseguirem com ações de penhora e execução de bens móveis. Com a prática, em 1885, a legislação relacionada à "adjudicação forçada" pôde ter como alternativa a penhora do fruto pendente e do fruto colhido (Martins 2010:46). 


\section{Referências bibliográficas}

ANDRADE, Manuel Correa de. 1980. A terra e o homem no Nordeste. 4. ed. São Paulo: Livraria Editora Ciências Humanas.

ANSELL, Aaron Michael. 2014. Zero hunger: political culture and antipoverty policy in Northeast Brazil. Chapel Hill: UNC Press Books.

BAILEY, F.G. 1971. Gifts and Poison. The Politics of Reputation. New York: Shocken Books.

BALEN; Maria Elisa \& FOTTA, Martin. 2019. "Introduction. Rearticulations of rural lives through conditional cash transfers". In: _ Money from the Government in Latin America Conditional Cash Transfer Programs and Rural Lives. New York: Routledge.

CRAIG, David Alan \& PORTER, Doug. 2006. Development beyond neoliberalism?: Governance, poverty reduction and political economy. Abingdon: Routledge.

COMERFORD, John. 2003. Como uma família: sociabilidade, territórios de parentesco e sindicalismo rural. Rio de Janeiro: Relume Dumará.

ESCOBAR, Arturo. 2010. "Histories of development, predicaments of modernity: thinking about globalization from some critical development studies perspectives". In: N. Long; Y. Jingzhong \& W. Yihuan (eds.), Rural transformations and development - China in Context. The everyday lives of policies and people. Cheltenham, UK: Edward Elgar Publishing Limited. pp. 25-53.

FERGUSON, James. 1994. The antipolitics machine: "development", depoliticization and bureaucratic power in Lesotho. Minneapolis: University of Minnesota Press.
FIRTH, Raymond. 1964. "Capital, Saving and Credit in Peasant Societies: A Viewpoint from Economic Anthropology". In: R. Firth \& B.S. Yamey (eds.), Capital, Saving and Credit in Peasant Societies. Studies from Asia, Oceania, The Caribbean and middle America. Chicago: Aldine Publishing Company. pp. 15-34.

GARCIA JR, Afrânio Raúl \& HEREDIA, Beatriz Alasia de. 2009. "Campesinato, família e diversidade de explorações agrícolas no Brasil". In: Emília Pietrafesa de Godoi; Marilda Aparecida de Menezes \& Rosa Acevedo Marin (orgs.), Diversidades de campesinatos: expressões e categorias. Vol. 2. São Paulo: Editora Unesp. pp. 213-243.

GEERTZ, Clifford. 1963. Peddlers and princes: Social development and economic change in two Indonesian towns. Chicago: University of Chicago Press.

GUANZIROLI, Carlos E. 2007. "PRONAF dez anos depois: resultados e perspectivas para o desenvolvimento rural". Revista de economia e sociologia rural, v. 45, n. 2:301-328.

GUDEMAN, S. \& RIVERA, A. 1990. Conversations in Colombia: the domestic economy in life and text. Cambridge: Cambridge University Press.

GRISA, Cátia. 2012. Políticas públicas para a Agricultura Familiar no Brasil: produção e institucionalização das ideias. Tese de Doutorado, CPDA/ UFRRJ.

JAMES, Deborah. 2014. Money from nothing: Indebtedness and aspiration in South Africa. Redwood City, California: Stanford University Press. 
LANNA, Ana Lúcia Duarte. 1986. “O café e o trabalho livre em Minas Gerais 1870-1920". Revista Brasileira de História, n. 12.

LONG, Norman. 2003. Development sociology: actor perspectives. Abingdon: Routledge.

MALINOWSKI, Bronislaw. 1978. Argonautas do Pacífico ocidental. Vol. 2. São Paulo: Abril Cultural.

MARTINS, José de Souza. 2010. O cativeiro da terra. 9. ed. São Paulo: Contexto.

MERCADANTE. Paulo. 1990. Crônica de uma comunidade cafeeira. Carangola: o vale e o rio. Belo Horizonte: Itatiaia.

MOSSE, David. 2005. Cultivating Development: An Ethnography of Aid Policy and Practice. Londres: Pluto.

MÜLLER, Lúcia. 2014. “Negotiating debts and gifts: financialization policies and the economic experiences of low-income social groups in Brazil". Vibrant: Virtual Brazilian Anthropology, v. 11, n. 1:191-221.

PEEBLES, Gustav. 2010 . "The anthropology of credit and debt". Annual Review of Anthropology, v. 39.
SAHLINS, Marshall. 1990. Ilhas de História. Trad. Barbara Sette. Rio de Janeiro: Jorge Zahar Editor.

SCOTT, James C. 2002. "Formas cotidianas da resistência camponesa". Revista Raízes, 21 (1):10-31.

SORRENTINO, Marcello. 2011. Development in the Mountains of Confusion: Guaribas under the ZeroHunger Programme. PhD thesis, Department of Anthropology of the London School of Economics for the degree of Doctor of Philosophy.

THOMPSON, Edward P. 1971. "The moral economy of the English crowd in the eighteenth century". Past \& present, n. 50:76-136.

VILLAREAL, Magdalena (ed.). 2004. Antropología de la deuda: crédito, ahorro, fiado y prestado en las finanzas cotidianas. Ciudad de Mexico: CIESA/ Miguel Angel Porrua.

WORLD BANK. 1975. Rural Development. Sector Policy Paper.

ZELIZER, Vivianna. 1994. The social meaning of money. Pin money, paychecks, poor relief, and other currencies. New York: BasicBooks. 


\section{O J OGO DO CAFÉ: OS SENTIDOS DO CRÉDITO/DÍVIDA NAS MONTANHAS DO CAPARAÓ MINEIRO}

\author{
THE COFFEE GAME: \\ THE MEANINGS OF CREDIT / DEBT \\ IN THE MOUNTAINS OF \\ CAPARAÓ MINEIRO
}

\section{Resumo}

O crédito/dívida é objeto privilegiado para a compreensão tanto das dinâmicas de reafirmação do capitalismo no tempo, quanto da democracia, ao passo em que se torna política pública de "inclusão financeira". No Brasil, nas duas últimas décadas, foi implantada e ampliada a oferta de crédito subsidiado para pequenos agricultores cuja base da mão de obra é familiar (Programa Nacional de Fortalecimento da Agricultura Familiar - Pronaf). Como parte de um estudo etnográfico realizado entre 19 unidades familiares de cafeicultores do Caparaó mineiro (2015-2018), abordarei neste artigo o acesso, a prática e os sentidos dados por esses "beneficiários" ao Pronaf. Demostrarei que o crédito/dívida é fator importante para a participação desses agricultores no chamado jogo do café, plano no qual as decisões da economia e do trabalho podem ser tomadas com maior autonomia. No entanto, ao mesmo tempo em que isso anuncia tempos melhores, também coloca para esses agricultores desafios e tensões constitutivas de um processo caracterizado por dilemas e aprendizados junto a sujeitos, artefatos, conceitos ligados direta e/ou indiretamente ao sentido capitalista do mercado, no qual diferentes sentidos dados à dívida compõem um debate crítico.

Palavras-chave: Crédito/dívida, Pronaf, Agricultura familiar, Caparaó.

\section{Abstract}

Credit/debt is an important object for understanding the dynamics of the reaffirmation of capitalism over time. It is crucial for comprehending democracies, as credit becomes a public policy that tackles "financial inclusion". In Brazil, during the last two decades, the provision of subsidized credit (State Credit) has been implemented and expanded to small farmers whose workforce is family-based (National Program for Strengthening Family Farming - Pronaf). In this article I address the access to, practice of and meanings ascribed to Pronaf by its "beneficiaries". I will demonstrate that credit / debt is a determinant of the role of small farmers into the so-called coffee game, a field wherein economic and labor decisions can be taken with greater autonomy. It also reveals certain tensions which might be constitutive of a local learning process, with people, artefacts and foreign concepts associated with market capitalism. Different notions of debt emerge as critical debates between the family farmers. Ethnographic research was conducted among 19 family units of Caparaó mineiro coffee farmers (2015-2018).

keywords: Credit/debt, Pronaf, Family farming, Caparaó, Brazil. 


\section{EL JUEGO DEL CAFÉ:}

\section{LOS SIGNIFICADOS DEL CRÉDITO/ DEUDA EN LAS MONTAÑAS DE CAPARAÓ MINEIRO}

\section{Resumen}

El crédito/deuda es un objeto privilegiado para comprender la dinámica de reafirmación del capitalismo a lo largo del tiempo. También es crucial para comprender la democracia contemporánea, ya que el crédito se convierte en una política pública que aborda la inclusión financiera. En Brasil, en las últimas dos décadas, la provisión de crédito subsidiado (State Credit) se ha implementado y ampliado a pequeños agricultores cuya fuerza laboral es familiar (Programa Nacional para Fortalecer la Agricultura Familiar - Pronaf). Como parte de un estudio etnográfico llevado a cabo entre 19 unidades familiares de cafeteros mineros Caparaó (2015-2018), abordaré en este artículo el acceso, la práctica y los significados que estos "beneficiarios" dan al Pronaf. Demostraré que el crédito / deuda es un factor importante en la entrada de estos agricultores en el llamado juego del café, donde las decisiones económicas y laborales pueden tomarse de manera más independiente. $\mathrm{Al}$ mismo tiempo que este juego anuncia tiempos mejores, también plantea algunas tensiones que podrían considerarse constitutivas de un proceso de aprendizaje local con personas, artefactos y conceptos extranjeros que podrían asociarse al capitalismo de mercado. Diferentes nociones de deuda surgen como debates críticos entre los agricultores familiares.

Palabra claves: Crédito/deuda, Pronaf, Agricultura familiar, Caparaó. 